\title{
Structural Changes Induced in Solid Dextran by Irradiation with Gamma Rays *
}

\author{
KIRSTI A. GRANATH and PER-OLOF KINELL** \\ Research Laboratories, Pharmacia Ltd., and Institute of Physical Chemistry, University of \\ Uppsala, Uppsala, Sweden
}

\begin{abstract}
Dextran samples with various molecular properties have been irradiated in air and in vacuum by cobalt-60 gamma rays. Degradation occurs as is evidenced from changes in molecular weight. The rate of degradation is faster in oxygen but less reproducible. The energy per broken bond is in vacuum the same for all samples $(19 \mathrm{eV})$ and it does not change with increasing dosage up to $18 \mathrm{Mrad}$. Gel filtration experiments have shown that irradiation in oxygen gives a molecular weight distribution which contains a larger weight fraction of low molecular material. Electron spin resonance data show that very stable free radicals are formed. A hypothesis has been put forward that primarily a radical ion is formed which then dissociates into a positive ion and an alkoxy radical. The change in branching during the degradation indicates that simultaneous bond scission and rearrangements of the molecules occur. An increase in branching is typical for molecules having an initially low degree of branching, while a high number of branches originally will lead to the formation of less branched molecules. This is explained as due to the spatial conditions along the chain. In all cases the polymolecularity of the samples increases during the degradation.
\end{abstract}

D extran intended for clinical use is generally obtained by acid hydrolysis and fractionation of raw dextran ${ }^{1}$. It is, however, also possible to achieve the necessary reduction in molecular weight of the original material by the action of enzymes ${ }^{2}$, ultrasonics ${ }^{3}$, and by means of high energy radiation ${ }^{4,5}$. The present investigation was carried out in order to study the changes occurring in the molecular properties of the material when subjected in the solid state to the ionizing action of the $\gamma$-rays from the isotope cobalt-60. This study has been concerned mainly with changes in the degree of branching and in the molecular heterogeneity at different doses of absorbed energy. It was, however, also considered useful if some information about the mechanism of the degradation could be obtained from electron spin resonance studies of

\footnotetext{
* Part of this investigation was presented at the First Nordic Meeting on Food Preservation by Ionizing Radiations, held at Risö, Denmark, 25-26th April, 1960 (Risö Report No. 16, p. 23).

** Present address: AB Atomenergi, Studsvik, Tystberga, Sweden.
}

Acta Chem. Scand. 15 (1961) No. 1 
the free radicals formed during the irradiation. Therefore, some measurements made with regard to this ${ }^{6}$ have been discussed in the present study.

Previous investigations on dextran exposed to ionizing radiation ( $\gamma$-rays) ${ }^{7}$ in both aqueous solution and in the solid state have shown that the rate of depolymerization in the former case is significantly faster than in the latter. Further, it was shown that the branching of the molecules did not change during the irradiation and therefore the degradation must predominantly take place through the breaking of the $1 \rightarrow 6$-glucosidic linkages. Lang et al. ${ }^{8}$ have shown ( $\gamma$-rays) that in aqueous solution the degradation rate decreases with increasing molecular weight. The depolymerization induced by irradiation of dilute aqueous solutions proceeds faster in the absence than in the presence of air ${ }^{9}$.

As regards the formation of additional degradation products, e.g. low molecular weight material from the glucose units, no such products have been identified after irradiation of dextran. On the other hand the existence of acidic groups in irradiated materials has been proven, e.g. for glucose ${ }^{\mathbf{1 0}}$, dextran ${ }^{10}$, and starch $^{11}$.

The molecular weight distribution of the dextran seems to be dependent upon the method of degradation: a broader distribution is obtained after irradiation than after acid hydrolysis ${ }^{8,12}$. The distribution can also change with the degree of degradation. This has been shown to be the case with polymethyl methacrylate treated in solution with ultrasonic waves ${ }^{13}$. In this case the heterogeneity passes a maximum during the intermediate phase of the degradation.

Samples that have been irradiated have given a lower value for the exponent $\boldsymbol{\alpha}$ in the viscosity molecular weight relation $\left([\eta]=K \cdot M^{\alpha}\right)^{4}$. This has been explained as due to a more dense molecular structure caused by increased branching during the irradiation. However, increased heterogeneity will also affect the $\alpha$ value in the same direction ${ }^{12}$ and, therefore, such an explanation cannot be regarded as adequately confirmed.

\section{EXPERIMENTAI}

Some preliminary irradiation experiments were performed in order to get information about the importance of the physical state of the samples and the influence of oxygen and moisture content. It was then found that both the size and density of the dextran grains and the oxygen content were significant factors. Moisture contents less than $5 \%$ did not seem to have any pronounced effect on the degradation. The latter result is, however, contrary to the findings on other polysaccharides for instance starch ${ }^{11}$ and cellulose ${ }^{14}$.

Samples. For the present work three dextran fractions were selected representing different degrees of branching and molecular heterogeneities. These samples included two partially hydrolyzed Swedish dextrans

$478-I-A$ with high molecular weight, very marked heterogeneity but moderately branched,

$823-327-V I$ with intermediate molecular weight, low heterogeneity and low degree of branching,

and one dextran of German origin

Onkotin 179 with low molecular weight, moderate heterogeneity but a high degree of branching.

The characterizing data on these samples, i.e. number and weight average molecular weights, heterogeneities and degrees of branching are given in Te ble 1.

Acta Chem. Scand. 15 (1961) No. 1 
Pretreatment. In order to eliminate as far as possible any dependence of the degradation rate on the size and porosity of the dextran particles all samples were pretreated in the same way. The polysaccharide was dissolved in distilled water to a $5 \%$ solution. This was then dropwise added to pure ethanol with continuous and vigorous stirring. The final ethanol concentration was adjusted to at least seven volumes ethanol per one volume original solution. By means of this procedure dextran was precipitated as fluffy flakes. These were filtered off and dried.

Irradiation. About $300 \mathrm{mg}$ of the dextran sample was placed in carefully cleaned glass ampoules. These were evacuated to about $0.01 \mathrm{~mm} \mathrm{Hg}$ pressure and heated to $60-70^{\circ} \mathrm{C}$ for several hours. The ampoules were then either hermetically closed directly or after the admittance of air. The irradiation was done in the gamma field from a 100 curie ${ }^{60} \mathrm{Co}$ freely radiating source described by Kinell and Larsson ${ }^{15}$. The dose rate was measured by the ferric ion dosimetry technique and was found to be about $60000 \mathrm{rad} / \mathrm{h}$ at the points where the ampoules were placed. The total dose was controlled by recording the irradiation time making due corrections for the decay of ${ }^{60} \mathrm{Co}$. The temperature was kept at $20^{\circ} \mathrm{C}$.

Number average molecular weight. The number average molecular weight, $M_{n}$, was determined by Somogyi's phosphate method ${ }^{16}$ using isomaltose as a standard. In this method the terminal aldehyde group of the dextran molecule reduces an alkaline copper phosphate reagent. As it was not immediately evident that reducing end-groups were formed during the degradation after irradiation as in acid hydrolysis, some check measurements were made. Applying Somogyi's method to glucose irradiated to a dose of 5.4 Mrad the true molecular weight of 180 was obtained (it has been found that at doses of $10-100$ Mrad some decomposition of the glucose molecule occurs ${ }^{17}$ ). This shows that the reducing groups are within experimental errors intact.

Further osmotic measurements were made on a dextran sample irradiated to a dose of 27 Mrad and then dialysed before the measurements. A molecular weight of 9500 was obtained compared to the value 8500 from Somogyi's method.

Weight average molecular weight. The weight average molecular weight, $M_{w}$, were determined by the light scattering technique using a Brice-Phoenix photometer and applying the same experimental procedure that has been described previously ${ }^{10}$.

Degree of branching. For this purpose the periodate oxidation method by Jeanes and Wilham ${ }^{20}$ in a modification earlier described ${ }^{19}$ was used. Due corrections were introduced for the amount of formic acid formed by the terminal end-groups.

Gel filtration experiments. In order to study the molecular weight distribution after irradiation the gel filtration method ${ }^{21,22}$ was used. The two samples investigated had been given a dose of about $18 \mathrm{Mrad}$, one of them in air and the other in vacuum. $5 \mathrm{ml}$ of a $10 \%$ solution was filtered through a column packed with a dextran gel (Sephadex, Pharmacia) having a water regain of $7.7 \mathrm{~g} / \mathrm{g}$. A number of fractions were collected and analyzed for their amount of dextran by the anthrone method ${ }^{23}$. The number average molecular weights were determined by the end-group method for some of the fractions.

\section{RESULTS}

Number of broken bonds. The number of broken bonds per monomer unit, i.e. the fracture density, $p$, induced by the radiation at a certain dose, $r$, has been calculated from the $M_{n}$ values.

Then

$$
p=m\left(\frac{1}{M_{n}}-\frac{1}{M_{n_{o}}}\right) \text {. }
$$

where $m$ is the molecular weight of the monomer unit and $M_{n_{o}}$ is the original molecular weight of the sample. The data obtained are collected in Table 1 . In Fig. 1 the $p$ values are given as a function of the dose in Mrad. The sensitivity towards radiation induced fracture as expressed through the proportionality factor $p_{o}$,

$$
p=p_{o} r
$$

Acta Chem. Scand. 15 (1961) No. 1 
Table 1. Degraaation data for dextran samples irradiated by cobalt-60 $\gamma$-rays. $r=$ dose in Mrad; $p=$ fracture density; $M_{n}$ and $M_{w}=$ number and weight averages of molecular weight; $q=$ number of $1 \rightarrow 6$-linkages per monomer unit.

\begin{tabular}{lllllll}
\hline$r$ & $M_{n}$ & $\frac{10^{6}}{M_{n}}$ & $p \cdot 10^{3}$ & $M_{w}$ & $\frac{M_{w}}{M_{n}}$ & $q$ \\
\hline
\end{tabular}

\begin{tabular}{crrr}
$478-\mathrm{I}-\mathrm{A}$ & irradiated in air. & \\
0 & 275000 & 3.6 & \multicolumn{1}{c}{0} \\
6.2 & 11200 & 89.3 & 13.9 \\
11.25 & 7700 & 130.5 & 20.5 \\
15.1 & 6800 & 147.0 & 23.2 \\
18.0 & 5200 & 192.0 & 30.5
\end{tabular}

478-I-A irradiated in vacuum.

$\begin{array}{lrrr}0 & 275000 & 3.6 & 0 \\ 7.3 & 22100 & 45.3 & 6.8 \\ 10.6 & 14800 & 68.0 & 10.4 \\ 14.0 & 12700 & 79.6 & 12.3 \\ 17.35 & 10300 & 96.7 & 15.1\end{array}$

$\begin{array}{rrrr}0 & 2180000 & 7.9 & 0.915 \\ 6.8 & 205000 & 9.3 & 0.895 \\ 10.4 & 134000 & 9.1 & 0.894 \\ 12.3 & 89300 & 7.1 & - \\ 15.1 & 69400 & 6.7 & 0.893\end{array}$

Onkotin 179 irradiated in air.

$\begin{array}{rrrr}0 & 33500 & 29.8 & 0 \\ 6.2 & 11800 & 84.7 & 8.9 \\ 13.5 & 7700 & 130.0 & 16.2\end{array}$

18.0

5700

174.2

23.4

2180000
300000
159000
105000
75800

$\begin{array}{rl}7.9 & 0.915 \\ 26.8 & 0.918 \\ 20.8 & 0.904 \\ 15.5 & 0.955 \\ 14.6 & 0.955\end{array}$

Onkotin 179 irradiated in vacuum.

$\begin{array}{rrrr}0 & 33500 & 29.8 & 0 \\ 4.5 & 19100 & 52.4 & 3.7 \\ 11.9 & 11000 & 90.6 & 9.9 \\ 18.4 & 8700 & 115.7 & 14.0\end{array}$

$\begin{array}{rrrr}0 & 125000 & 3.7 & 0.700 \\ 3.7 & 77500 & 4.1 & 0.785 \\ 9.9 & 66700 & 6.0 & 0.794 \\ 14.0 & 52600 & 6.1 & 0.803\end{array}$

$823-327-V I$ irradiated in air.

$\begin{array}{rrrr}0 & 106000 & 9.4 & 0 \\ 2.1 & 21900 & 45.7 & 5.9 \\ 4.1 & 13500 & 74.0 & 10.5 \\ 7.0 & 9500 & 105.2 & 15.5 \\ 12.1 & 6150 & 162.6 & 24.8 \\ 17.1 & 5300 & 190.4 & 29.3\end{array}$

143000

90900

74600

63300

55200

42600

$\begin{array}{lc}1.3 & 0.940 \\ 4.2 & - \\ 5.5 & 0.889 \\ 6.7 & 0.910 \\ 9.0 & 0.931 \\ 8.1 & -\end{array}$

$823-327-V I$ irradiated in vacuum.

$\begin{array}{cccc}3-327-V I & \text { irradiated in vacuum. } & \\ 0 & 106000 & 9.4 & 0 \\ 3.1 & 30300 & 336 & 3.9 \\ 6.0 & 21300 & 46.9 & 6.1 \\ 11.3 & 14200 & 70.8 & 10.0 \\ 14.0 & 12100 & 827 & 11.9 \\ 18.1 & 11100 & 89.7 & 13.0\end{array}$

143000

$1.3 \quad 0.940$

94300

79400

66200

52600

50500

$\begin{array}{ll}3.1 & 0.896 \\ 3.7 & 0.913 \\ 4.7 & 0.915 \\ 4.4 & 0.902 \\ 4.5 & 0.908\end{array}$

is higher in the presence of oxygen than in vacuum. The non-linear dependence of $p$ on $r$ for samples 478- I-A and 823-327-VI is not definitely ascertained. The difference between these two samples and Onkotin 179 may depend upon different accessibilities of various parts of the polymer in a degradation mechanism, where the presence of oxygen is important. In vacuum all three samples show the same behaviour within experimental errors. The $p_{o}$ values per Mrad radiation dose are given in Table 2. 


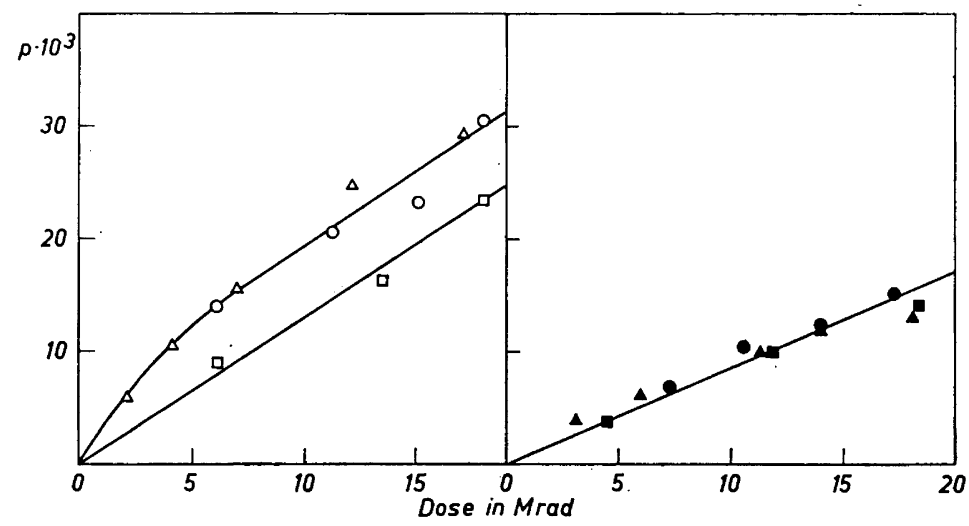

Fig. 1. The fracture density as a function of radiation dose. The following notations have been used

$\begin{array}{lcc}\text { Sample } & \text { Air } & \text { Vacuum } \\ 478-\text { I }-A & O & \text { O } \\ 823-327-\text { VI } & \triangle & \square \\ \text { Onkotin } 179 & \square & \end{array}$

Radiation yield. From the $p_{0}$ values the yield of fractures per $100 \mathrm{eV}, G$, can easily be calculated ${ }^{24}$,

$$
G=0.96 \times 10^{6} \frac{p_{o}}{m}
$$

The data are given in Table 2. These values compare with the value $G=7.1$ obtained from data on irradiation of dextran with $800 \mathrm{keV}$ electrons ${ }^{4}$ and $G=10$ for cellulose ${ }^{25}$. For amylopectin the value $G=14.5$ has been reported ${ }^{11}$. Converting the $G$ values into energies per bond fracture we get the values in the last column of Table 2 .

Degree of branching. The degree of branching of the dextran molecules measured as the number, $q$, of $1 \rightarrow 6$ linkages is also given in Table 1 . The most

Table 2. Radiation yield data for dextran.

\begin{tabular}{|c|c|c|c|}
\hline Sample & $\begin{array}{c}\text { Fracture density } \\
\text { per unit dose (in Mrad) }\end{array}$ & $\begin{array}{c}G \text { value } \\
\text { Fractures } / 100 \mathrm{eV}\end{array}$ & $\begin{array}{c}\text { Energy per broken } \\
\text { bond eV }\end{array}$ \\
\hline \multicolumn{4}{|l|}{ Air: } \\
\hline $\left.\begin{array}{l}478-\mathrm{I}-\mathrm{A} \\
823-327-\mathrm{VI}\end{array}\right\}$ & $\sim 1.8 \times 10^{-3}$ & 11 & $\sim 9$ \\
\hline \multicolumn{2}{|l|}{ Vacuum: } & 7.7 & 13 \\
\hline $\left.\begin{array}{l}478-\mathrm{I}-\mathrm{A} \\
823-327-\mathrm{VI} \\
\text { Onkotin } 179\end{array}\right\}$ & $0.87 \times 10^{-3}$ & 5.2 & 19 \\
\hline $\begin{array}{l}\text { Dextran } \\
\text { Cellulose } 25\end{array}$ & $\overline{-}$ & - & $\begin{array}{l}14 \\
10\end{array}$ \\
\hline Amylopectin ${ }^{11}$ & - & - & 7 \\
\hline
\end{tabular}

Acta Chem. Scand. 15 (1961) No. 1 


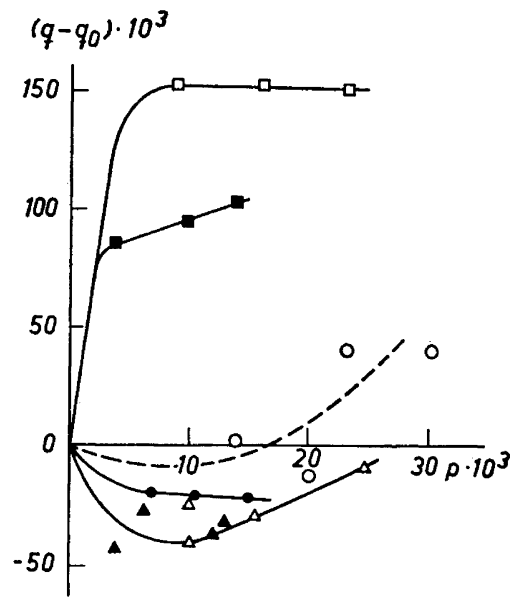

Fig. 2. Change in number of branches as a function of the fracture density. For symbols cf. Fig. 1

highly branched species is Onkotin 179. Samples 478-I-A and Onkotin 179 show a decrease in degree of branching when irradiated in air. In vacuum 478-I-A becomes more branched as the radiation dose increases but for Onkotin 179 the number of branches still decreases. Both in air and in vacuum the degree of branching of sample 823-327-VI increases at low doses, whereas at higher doses it has a tendency to decrease. The change of the degree of branching, given as the quantity $q-q_{0}$, with the fracture density, $p$, is given in Fig. 2.
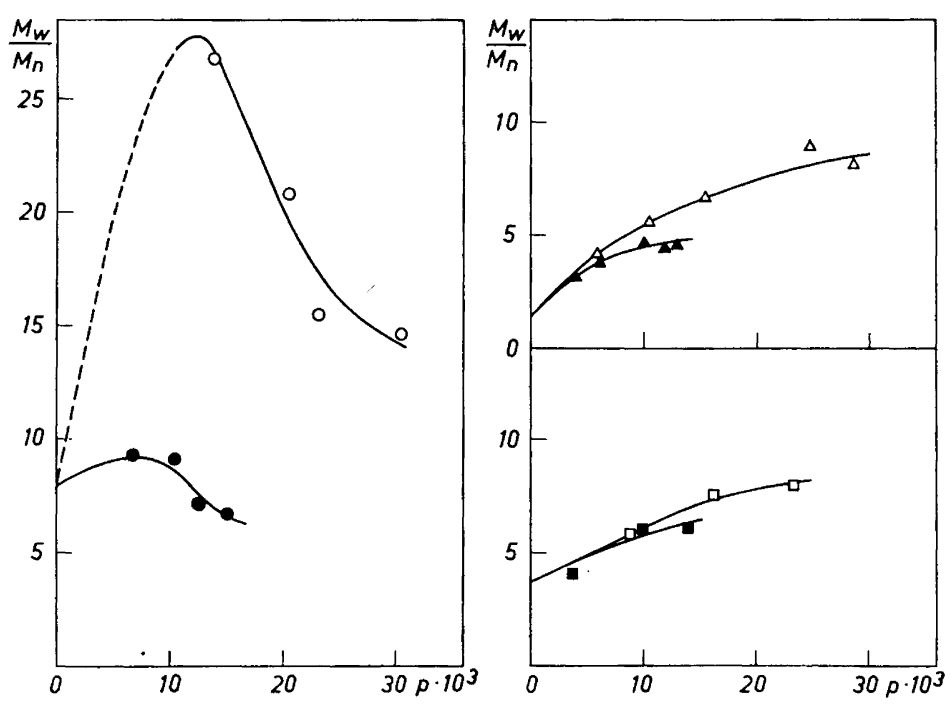

Fig. 3. Polymolecularity measured as $M_{w} / M_{n}$ as a function of fracture density. For symbols $c f$. Fig. 1 .

Acta Chem. Scand. 15 (1961) No. 1 

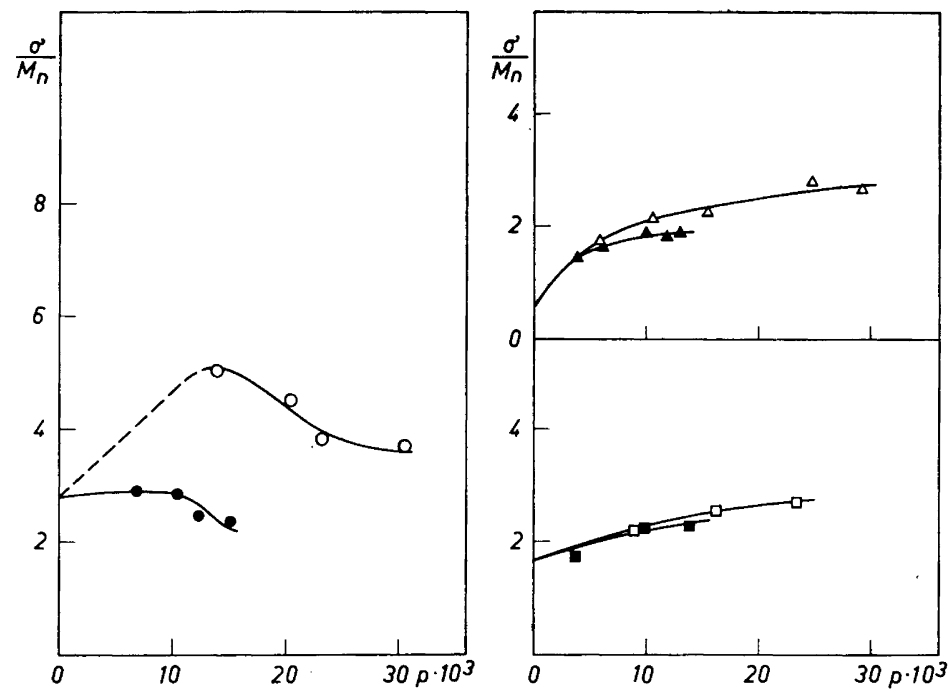

Fig. 4. Polymolecularity, measured as $\sigma / M_{n}$, as a function of fracture density. For symbols $c f$. Fig. 1.

Polymolecularity. The change in molecular weight distribution during the degradation has been measured as the ratio $M_{w} / M_{n}$. The values obtained are given in Table 1. In Fig. 3 the variation with the fracture density is given. As a further measure of the heterogeneity the quantity $\sigma / M_{n}$, where $\sigma=\sqrt{M_{n}\left(M_{w}-\bar{M}_{n}\right)}$ is the mean deviation from the number average molecular weight, has been used and plotted against the fracture density in Fig. 4. The molecular weight distributions for the two samples of 478-I-A irradiated

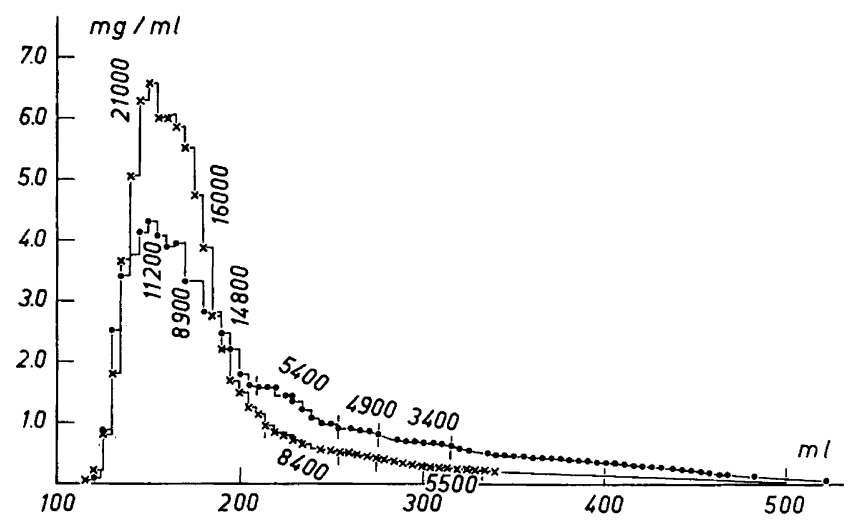

Fig. 5. Distribution curves from gel filtration experiments. in air.

Acta Chem. Scand. 15 (1961) No. 1 
Table 3. Number average molecular weights of some fractions obtained by using the gel filtration technique on samples from $478-\mathrm{I}-\mathrm{A}$.

Irradiation in vacuum

Dose: 17.35 Mrad. $M_{w} / M_{n}=6.7$
Irradiation in air

Dose: $18.0 \mathrm{Mrad}$. $M_{w} / M_{n}=14.6$

\begin{tabular}{crrr}
\hline $\begin{array}{c}\text { Amount of fraction } \\
\%\end{array}$ & $M_{n}$ & $\begin{array}{c}\text { Amount of fraction } \\
\%\end{array}$ & $M_{n}$ \\
\hline & & & \\
3.0 & 21000 & 9.3 & $>11200$ \\
17.6 & 16000 & 24.6 & 11200 \\
10.0 & 14800 & 12.9 & 8900 \\
7.0 & 8400 & 11.6 & 5400 \\
3.8 & 5500 & 4.2 & 4900 \\
5.0 & 5500 & 7.9 & 3400 \\
\hline
\end{tabular}

to $18 \mathrm{Mrad}$ are given in Fig. 5. Some pertinent data for these samples are also given in Table 3 .

Electron spin resonance measurements. Some studies have been undertaken in order to get information about the free radicals formed during the irradiation of dextran ${ }^{6}$. Irradiated samples were investigated both for the number of free radicals formed and for their structure. The number was found to be proportional to the dose given. The resonance spectrum obtained is shown in Fig. 6. It corresponded to a $g$ value of 2.005 and the line width was 26 gauss. The line has a hyperfine splitting which is quite evident but not very well resolved. The splitting was estimated to $3-6$ gauss. The life time of the radicals was measured at $20^{\circ} \mathrm{C}$ and $50^{\circ} \mathrm{C}$. The decay was found to be very slow at the lower temperature and a change was hardly detectable: a half life of about 12.5 weeks was estimated. At the higher temperature a more rapid decay was observed during the first day, half life $8.5 \mathrm{~h}$. Later the decay was considerably reduced: half life 12.5 days. The decay curve at $50^{\circ} \mathrm{C}$ is given in Fig. 7 .

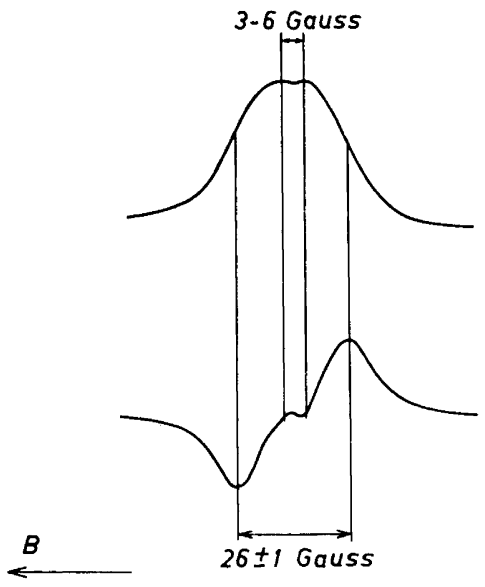

Fig. 6. Spin resonance spectrum of irradiated dextran. The arrow indicates increasing magnetic field. 


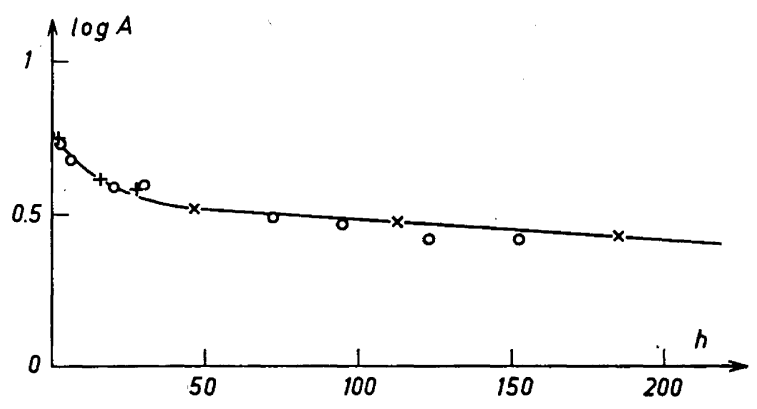

Fig. 7. Decay curve for free radicals at $50^{\circ} \mathrm{C}$. A is the number of free radicals. The doses are: $4 \operatorname{Mrad}(0), 6.5 \operatorname{Mrad}(+)$.

\section{DISCUSSION}

An essential point in the present work is the correct determination of the number of broken bonds. Each broken linkage between two glucose units will increase the number of molecules by one. The number of molecules counted after a certain dose of radiation depends upon the type of end-group formed because of the chemical end-group method employed. Somogyi's method only detects reducing end-groups, i.e. groups having the configuration

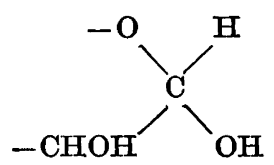

at carbon atom number 1 . If other types of end-groups are formed an error will be introduced. The necessary condition for obtaining reducing endgroups is that one hydrogen atom and one hydroxyl group are present and that these can be attached to the $\mathrm{O}$ and $\mathrm{C}$ atoms of the broken glucosidic linkage. A reducing group could be formed by intramolecular transfer of a hydrogen atom over a $\mathrm{C}-\mathrm{C}$ bond distance but that process would introduce steric strain in the hydrogen donor glucose unit and is therefore unlikely to occur. If the degradation reaction proceeded predominantly in the solid phase one would expect the water content in the material to exert a pronounced effect. This is not the case. With respect to the long half life of the free radicals formed in the solid state only very slow reactions in which these radicals take part are likely to occur. Therefore, most of the energy deposited in the solid samples through the radiation is probably stored and possible reactions only start when the samples are dissolved in water. Then reducing end-groups can be formed because there is no lack of water. The irradiation of glucose shows that the reducing groups themselves are not influenced by the radiation. The rather good agreement between the molecular weight values obtained by Somogyi's method and the osmotic measurement gives no evidence that any appreciable errors should be introduced when using Somogyi's method for obtaining the number of broken bonds.

Acta Chem. Scand. 15 (1961) No. 1 
The influence of oxygen on the degradation is not very easy to interpret. The reproducibility seems to be low and also the size of the dextran grains appears of importance. The results from the gel filtration fractionation shows that the molecular weight distribution is not exactly the same after degradation in air and in vacuum. The weight fraction of low molecular weight material is higher after irradiation in air.

The radiation yields given in Table 2 correspond to an energy per broken bond of the order of $10-20 \mathrm{eV}$. This value is much higher than the real bond energy. Some significant values are, $3.64 \mathrm{eV}$ for $\mathrm{C}-\mathrm{C}$ bonds, $3.45 \mathrm{eV}$ for $\mathrm{C}-\mathrm{O}$ bonds and $4.54 \mathrm{eV}$ for $\mathrm{O}-\mathrm{H}$ bonds. From these figures it seems most reasonably to presume a higher probability of cleavage for $\mathrm{C}-\mathrm{C}$ or $\mathrm{C}-\mathrm{O}$ bonds. On the other hand these figures refer to the formation of bonds in molecules in their ground state. The conditions must be quite different when the molecule is excited or ionized. The first ionization potential for organic molecules is around $10 \mathrm{eV}$. This is the lowest amount of energy that must be transferred to the molecule from the gamma quantum in order to produce an ionization. In practice about three times this value is necessary for the formation of an ion pair.

Chain scission will only occur for broken C-O bonds outside the glucose unit, i.e. in the glucosidic links. If the immediate result of the gamma quantum is to remove one of the $p_{z}$ electrons from the ether oxygen then the following two radical ions can be formed

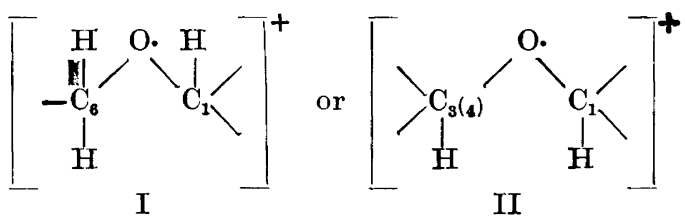

depending upon which type of glucosidic linkage is attacked. In this connection it may be mentioned that the binding energy of $1 \rightarrow 4$-linkages is about $0.13 \mathrm{eV}(3 \mathrm{kcal} / \mathrm{mole})$ lower than the binding energy of a $1 \rightarrow 6$-linkage ${ }^{26}$. Further it has been observed that $1 \rightarrow 4$-linkages break down about four times faster than $1 \rightarrow 6$-linkages ${ }^{27}$. As the $1 \rightarrow 4$ - and $1 \rightarrow 3$-linkages are very similar, the $1 \rightarrow 3$-linkage is also probably weaker than the $1 \rightarrow 6$-linkage. The radical ion may dissociate into one free radical and one positive ion<smiles>CC[C@H](C)[CH+]C(C)C</smiles>

When examining the electron spin resonance spectra, one finds that the observed hyperfine structure may indicate a weak interaction with one proton spin. It means that the electron spin density for the carbon atom $\mathrm{C}_{1}$ might attain a low value but in the radical ions it would have to be zero for the $C_{3}$ and $\mathrm{C}_{6}$ carbon atoms. Alkoxy radicals of the type $\mathrm{RO}$. exhibit a hyperfine 
pattern which suggests weak interaction with the $\alpha$ hydrogens but negligible interaction with the $\beta$ hydrogens ${ }^{28}$. Due to the proximity of the $\mathrm{C}_{1}$ carbon atom to another oxygen atom the coupling of the electron spin to the proton spins of the hydrogens at the $\mathrm{C}_{3}$ and $\mathrm{C}_{6}$ carbon atoms may be still more reduced. Then either of the radicals I and II or the radical formed during the dissociation would have a structure in accordance with the electron spin resonance spectrum. Further the absence of any additional hyperfine structure with lines separated by $20-30$ gauss typical for hydrocarbon radicals would support the hypothesis put forward in the reaction (1) that a positive hydrocarbon-like ion is formed. There is nothing in the existing data which contradicts the possibility that this reaction proceeds in solid material. When dissolving the irradiated dextran in water the following reactions may occur,

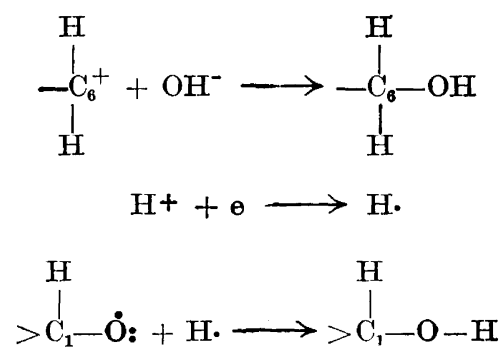

The last group constitutes a reducing end-group. The hypothesis presented here for the cleavage process of the glucosidic bonds is only a tentative approach to a certainly very complicated mechanism.

That the changes are rather complicated is evident from the changes in degree of branching occurring during the degradation process. The variation of the number of branches per monomer unit (the $q-q_{0}$ values in Fig. 2) during the irradiation differs very much between the three samples. Onkotin 179 has a high original degree of branching and it undergoes a considerable degradation as far as the branches are concerned during the first part of the breakdown process. In the presence of oxygen the unbranching will finally cease. In vacuum degradation proceeds continually but at a much lower rate. The behaviour of sample 478-I-A in air is not very clear. Initially the degree of branching seems to remain constant but subsequently unbranching probably begins. In vacuum the number of branches per monomer increases at the same time as the fracture density increases. For the sample 823-327VI the enhanced degree of branching is quite evident both in the presence of air and in vacuum. The degree of branching has an optimum value after which it starts to decrease. It is evident that rather complicated processes must occur and the behaviour of the samples can only be explained if it is assumed that the units which once have been cut off have the ability to reunite with the macromolecules at different points. What is happening is then a combined degradation and rearrangement. In Onkotin 179 which is heavily branched the cut off units are most likely rather small ${ }^{29}$. These units will preferably be attached to the chain ends because of the limited space available along the chains. Finally a structure of the polymer molecule is

Acta Chem. Scand. 15 (1961) No. 1 
obtained which undergoes a "normal" degradation. In the case of 478-I-A in vacuum and 823-327-VI both in vacuum and in air the cut off units will preferably attach themselves to glucose units somewhere along the chain to form new branches. The initially low degree of branching of these samples gives the spatial requirements for favouring such an attachment. After a certain degree of branching has been reached the probability for branch formation along the chain is reduced and then attachement to the chain end will start to dominate, which results in a lowering of the degree of branching in the same way as for Onkotin 179. It should be mentioned that the same general connection between initial degree of branching and the branching behaviour during degradation has also been found in acid hydrolysis of dextran ${ }^{12}$. The possibility of branching through rearrangement has previously been discussed for dextran molecules ${ }^{30}$ but mainly with regard to its influence on the molecular properties. This problem of degradation and increase in degree of branching is evidently closely related to the question of simultaneous bond scission and crosslinking.

Figs. 3 and 4 give the general behaviour of the samples as far as changes in polymolecularity are concerned. All three samples show the same tendency to become more polymolecular when degradation increases. In air the heterogeneity of sample 478-I-A reaches a maximum after which the sample becomes progressively more homogeneous. The other two samples show little difference between irradiation in air and in vacuum but a tendency to form a maximum heterogeneity is exhibited. The higher polymolecularities in air compared to vacuum indicates that in the presence of oxygen smaller fragments are cut off. This will effect the $M_{n}$ value more than the $M_{w}$ value. Also with respect to polymolecularity the acid hydrolysis gives the same general picture $^{12}$.

Acknowledgements. The authors are much indebted to Professors The Svedberg, Stig Claesson, and Kai Siegbahn for their interest in this work and for the facilities put at their disposel.

\section{REFERENCES}

1. Ingelman, B. and Halling, M. Arkiv Kemi 1 (1949) 61.

2. Ingelman, B. Acta Chem. Scand. 2 (1948) 803.

3. Stacey, M. Research 4 (1951) 48. Lockwood, A. Chem. \& Ind. London 195146.

4. Price, F., Bellamy, W. and Lawton, E. J. Phys. Chem. 58 (1954) 21.

5. U.S. Patent $2,867,571$ (1959).

6. Kinell, P.-O., Granath, K. and Vänngård, T. Arkiv Fysik 13 (1958) 272.

7. Ricketts, C. and Rowe, C. Chem. \& Ind. London 1954189.

8. Lang, R., Schmitt, E., Henley, E. and Gaden, E. Termination Report (1956) April 15, United States Atomic Energy Comm.

9. Phillips, G. and Moody, G. J. Chem. Soc. 19583534.

10. Moody, G. and Phillips, G. Chem. \& Ind. London 19591247.

11. Ehrenberg, L., Jaarma, M. and Zimmer, E. Acta Chem. Scand. 11 (1957) 950.

12. Granath, K. Unpublished.

13. Schmid, G., Schneider, Ch. and Henglein, A. Kolloid. Z. 148 (1956) 73.

14. Scocca, P. and Brenner, F. Abstr. of Papers, ACS Meeting 122, Sept. 1952.

15. Kinell, P.-O. and Larsson, B. Risö Report No. 16 (1960) p. 9.

16. Isbell, H., Snyder, C., Holt, N. and Dryden, M. J. Research Natl. Bur. Standards 50 (1953) 81 . 
17. Saeman, J., Millett, M. and Lawton, E. Ind. Eng. Chem. 44 (1952) 2848.

18. Peat, S., Whelan, W. and Roberts, J. J. Chem. Soc. 19562258.

19. Granath, K. J. Colloid. Sci. 13 (1958) 308.

20. Jeanes, A. and Wilham, C. J. Am. Chem. Soc. 72 (1950) 2655.

21. Porath, J. and Flodin, P. Nature 183 (1959) 1657.

22. Flodin, P. and Granath, K. Symposium über Makromolekiile, Wiesbaden 1959.

23. Scott, T. and Melvin, E. Anal. Chem. 25 (1953) 1656.

24. Charlesby, A. Atomic Radiation and Polymers, Pergamon Press, Oxford 1960, p. 137.

25. Ref. ${ }^{24}$, p. 361 .

26. Jeanes, A., Schieltz, N. and Wilham, C. J. Biol. Chem. 176 (1948) 617.

27. Swanson, M. and Cori, C. J. Biol. Chem. 172 (1948) 797; Carlqvist, B. Acta Chem. Scand. 2 (1948) 759.

28. Technical Information Bulletin from the Radio-Frequency Spectroscopy Laboratories of the Instrument Division, Varian Associates, Palo Alto, Calif. 2 (1959) No. 4.

29. Van Cleve, J., Schaefer, W. and Rist, C. J. Am. Chem. Soc. 78 (1956) 4435.

30. Bovey, F. J. Polymer Sci 35 (1959) 183.

Received September 8, 1960. 